\title{
Systems Modeling and Analysis of Heavy Ion Drivers for Inertial Fusion Energy
}

\author{
W R. Meie1
}

This paper was prepared for submittal to the 1998 American Nuclear Society Annual Meeting

Nashville, TN

June 7-11, 1998

June 3, 1998

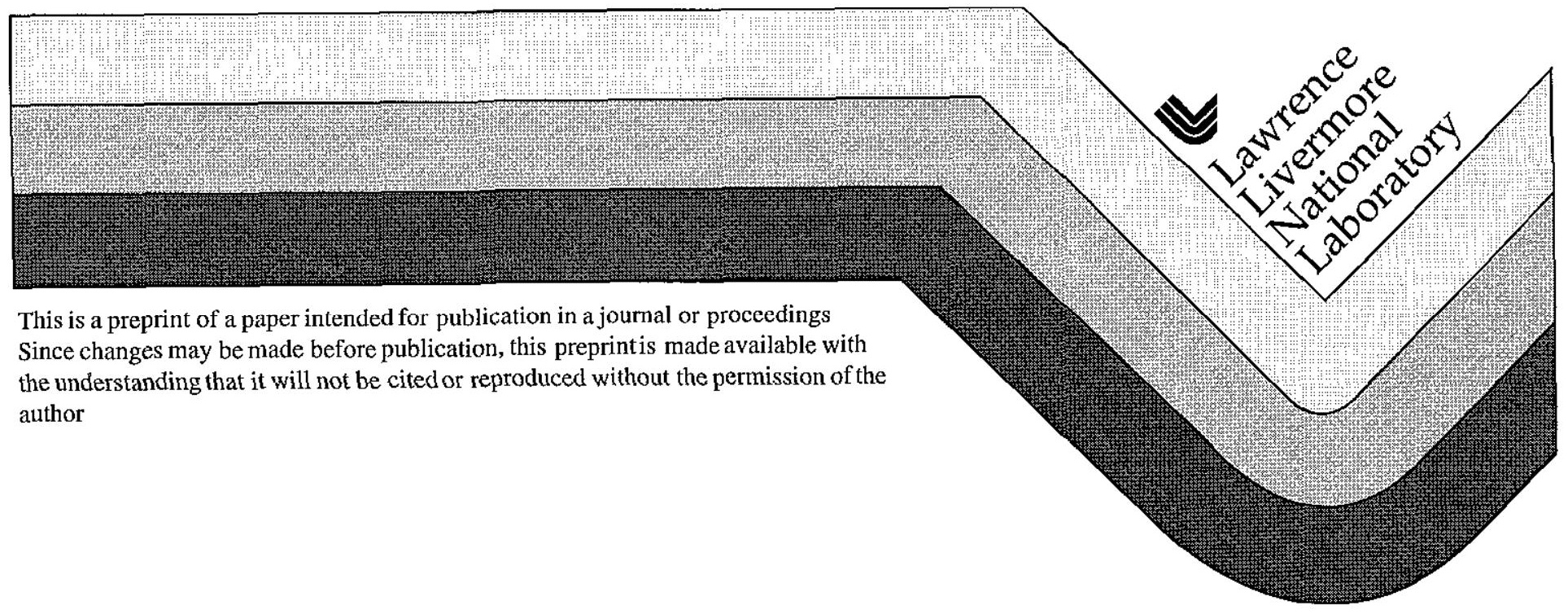




\section{DISCLAIMER}

This document was prepared as an account of work sponsored by an agency of the United States Government Neither the United States Government nor the University of California nor any of their employees, makes any warranty, express or implied, or assumes any legal liability or responsibility for the accuracy, completeness, or usefulness of any information, apparatus, product, or process disclosed, or represents that its use would not infringe privately owned rights Reference herein to any specific commercial product, process, or service by trade name, trademark, manufacturer, or otherwise, does not necessarily constitute or imply its endorsement, recommendation, or favoring by the United States Government or the University of California The views and opinions of authors expressed herein do not necessarily state or reflect those of the United States Government or the University of California, and shall not be used for advertising or product endorsement purposes 


\title{
SYSTEMS MODELING AND ANALYSIS OF HEAVY ION DRIVERS FOR INERTIAL FUSION ENERGY
}

\author{
Wayne R Meier \\ Lawrence Livermore National Laboratory \\ P O Box $808, \mathrm{~L}-481$ \\ Livermore, California 94551
}

(925) $422-8536$

\begin{abstract}
A computer model for systems analysis of heavy ion drivers based on induction linac technology has been used to evaluate driver designs for inertial fusion energy (IFE) Design parameters and estimated costs have been determined for drivers with various ions, different charge states, different front-end designs, with and without beam merging, and various pulse compression and acceleration schedules We have examined the sensitivity of the results to variations in component cost assumptions, design constraints, and selected design parameters
\end{abstract}

\section{INTRODUCTION}

HIBEAM (Heavy Ion Beams for Energy Applications Model) is an integrated source-to-target computer model for induction linac drivers for IFE that includes the key interdependencies of the major subsystems in terms of cost, performance and constraints ${ }^{1}$ We are using this model to investigate design options for drivers for IFE power plants Our objects are to find minimum cost configurations that meet specified target requirements and to identify factors that have the highest leverage for cost reduction Previous systems modeling and conceptual design studies for HIF drivers can be found in Refs 2-6

The models in HIBEAM are, for the most part, based on current technologies with assumptions for technology improvements and component cost reductions that might be possible by the time a driver is built There is a lack of consensus as to the validity of some of these assumptions, some feel we have be much too conservative, while others believe we have been too optimistic Some of the models, e g, the final focusing algorithms, are based on early work in the field that has not been adequately dealt with in the
HIF program, thus leading to significant uncertainties In addition, entirely new technologies or significant advances are possible, e g, we have not yet considered the impact of using high temperature superconductors on the design and cost Some of the uncertainties have been addressed in our sensitivity studies, which are useful in identifying areas where technology improvements and/or major cost reductions could have a significant impact The reader is advised, therefore, to focus more on the cost trends than the actual cost values Despite these limitations, we feel it has been valuable to "put all the pieces together" to see where we stand

As a starting point, we developed a design configuration that met the requirements of a recently developed target design (see Table I) ${ }^{7-9}$ The results of our initial modeling efforts and a description of our original point design are given in Ref 10 . The design includes a 192-beam injector feeding an electrostaticfocusing accelerator section, four-to-one beam merging and transition to a magnetic-focusing accelerator section at $100 \mathrm{MeV}$ Of the 48 beams in the magnetic focus section, 16 beams are accelerated to $3 \mathrm{GeV}$ and are used for a $30 \mathrm{~ns}$ prepulse on target, while the remaining 32 beams are accelerated to $4 \mathrm{GeV}$ and form the $8 \mathrm{~ns}$ main pulse The total beam energy at the end of acceleration is $59 \mathrm{MJ}$ The main accelerator is followed by final transport and final focus sections The final transport section provides the distance needed for drift compression (to get the required pulse length on target) and realignment of the beams for two-sided illumination The final focus section includes the final focus quadrupoles that are used to first expand the beam radially and then focus it to a small spot on target The direct capital cost was estimated to be $\sim \$ 13 \mathrm{~B}$ for this case 
Table I Requirements of one particular target design

\begin{tabular}{|l|c|c|}
\hline & Prepulse & Main Pulse \\
\hline Ion mass, amu & \multicolumn{2}{|c|}{200} \\
\hline Final ion energy, GeV & 30 & 40 \\
\hline Beam energy, MJ & 16 & 43 \\
\hline Total charge, mC & 053 & 107 \\
\hline Pulse duration on target, ns & 30 & 8 \\
\hline Spot radius on target, mm & \multicolumn{2}{|c|}{27} \\
\hline Target yield, MJ & \multicolumn{2}{|c|}{$\sim 400$} \\
\hline Target gain & \multicolumn{2}{|c|}{$\sim 70$} \\
\hline
\end{tabular}

We have examined variations of the original point design including lower mass ions, higher charge state ions, different front-end designs (using solenoids or magnetic quadrupoles), elimination of merging, various pulse compression and acceleration schedules, etc We have also examined the sensitivity of the results to variations in component cost assumptions, design constraints, and selected design parameters, such as the total driver energy These results are reported in this paper

\section{DIFFERENT FRONT END OPTIONS}

\section{A Using Solenoids in the Low Energy End}

We investigated replacing the electrostatic quad focusing section at the low energy end of the accelerator with solenoids The idea was to take advantage of solenoids' ability to carry large currents and thus eliminate the need for beam merging (Recall the original design had 192 beams in the electrostatic section $\left(\mathrm{T}_{\text {ion }}<\right.$ $100 \mathrm{MeV}$ ) and 48 beams in the magnetic quad focusing section) We did not find a particularly good case for solenoids At higher energy, our models lead to a preference for a large number of small quadrupoles Solenoid scaling, however, favors fewer, large beams Since the number of beams in the solenoid and quad sections is the same, neither section is optimized, and resulting costs are higher than the original design. We considered three cases singly charged $\mathrm{Pb}$ with a 1 A/beam initial current, singly charged $\mathrm{Xe}(\mathrm{A}=131)$ with a $19 \mathrm{~A} /$ beam initial current, and $\mathrm{Xe}^{+8}$, with a 19 A/beam initial current The results are summarized in Table II Only the $\mathrm{Xe}^{+8}$ case had a lower cost than the original design, but this was due to the lower mass-tocharge ratio, not to the use of solenoids

\section{B Using Magnetic Quads in the Low Energy End}

The cost of the induction cores was a significant component in the original point design It was postulated that by eliminating the electrostatic section and using magnetic quad focusing from the very beginning, we
Table II Comparison of original design to drivers using solenoids at the low energy end of the accelerator

\begin{tabular}{|l|c|c|c|c|}
\hline Configuration $^{\mathrm{a}}$ & $\begin{array}{c}\mathrm{ESQ} / \\
\mathrm{MQ}\end{array}$ & $\begin{array}{c}\mathrm{SOL} / \\
\mathrm{MQ}\end{array}$ & $\begin{array}{c}\text { SOL/ } \\
\mathrm{MQ}\end{array}$ & $\begin{array}{c}\text { SOL/ } \\
\mathrm{MQ}\end{array}$ \\
\hline Total beam energy, MJ & 5.9 & 59 & 59 & 5.9 \\
\hline Ion mass, amu & 200 & 200 & 132 & 132 \\
\hline Charge state & 1 & 1 & 1 & 8 \\
\hline Initial current, A & 03 & 1 & 19 & 19 \\
\hline Number of beams & $192 /$ & $80 /$ & $8 /$ & $128 /$ \\
Front-end/MQ sections & 48 & 80 & 8 & 128 \\
\hline Trans to MQ, MeV & 100 & 50 & 100 & 100 \\
\hline Total direct cost, \$B & 13 & 1.8 & 17 & 1.0 \\
\hline
\end{tabular}

${ }^{\mathrm{a}} \mathrm{ESQ}=$ Electrostatic quads, $\mathrm{MQ}=$ Magnetic quads, $\mathrm{SOL}=$ Solenoids

would be able to reduce the length of the pulse and possibly reduce the required volt-seconds and metglas cost Our most recent calculations using this approach, give a driver cost of about the same as the original architecture, \$1 $3 \mathrm{~B}$ The system optimized at somewhat higher number of beams, 60 , over the entire length of the accelerator This change did reduce the mass of metglas and cost of cores by $18 \%$, but the savings was balanced by increased transport costs compared to using electrostatic focusing for $\mathrm{T}_{\text {ion }}<100 \mathrm{MeV}$

\section{LOWER MASS IONS AND HIGHER CHARGE STATE}

Drivers using lower mass ions were also investigated For these cases, the accelerator uses magnetic focusing over the entire length For each driver energy and ion, the optimum initial pulse duration, number of beams, quad field in the accelerator, and quad field in the drift compression section are determined The ion energy was adjusted with each ion to give the proper range in the target radiator (lower range for low mass ions)

The optimum number of beams (to the nearest 10) and initial pulse duration (to within $5 \mu$ s) along with the resulting direct capital costs of the drivers are given in Table III The driver direct costs are plotted in Fig 1 In the $15-59 \mathrm{MJ}$ range, the cost scaling is very nearly linear with a non-zero intercept As indicated, a $03 \mathrm{MJ}$ point was calculated for $\mathrm{Kr}^{+1}$, and the cost does show some drop below linear as the driver energy approaches zero The lowest line is the $\mathrm{K}^{+1}$ case

The reference case distributed radiator target requires a target spot size of $27 \mathrm{~mm}$ for a driver energy of $5.9 \mathrm{MJ}$ The $\mathrm{Pb}^{+1}, \mathrm{Xe}^{+1}$ and $\mathrm{Kr}^{+1}$ cases can all meet this requirement assuming 95-99\% neutralized transport and a focus length of $5 \mathrm{~m}$. If the spot size is significantly 
Table III Driver design parameters and costs for various ions

\begin{tabular}{|l|c|c|c|c|c|c|}
\hline Ion & $\mathbf{N e}$ & $\mathbf{K}$ & $\mathbf{K r}$ & $\mathbf{X e}$ & $\mathbf{X e}$ & Pb-like \\
\hline Ion mass, amu & 20 & 39 & 84 & 131 & 131 & 200 \\
\hline Charge state & 1 & 1 & 1 & 1 & 8 & 1 \\
\hline Injector energy, MeV & 3 & 3 & 3 & 3 & 24 & 3 \\
\hline Final ion energy, GeV & & & & & & \\
\hline Prepulse & 0.16 & 0.45 & 1.1 & 19 & 19 & 30 \\
\hline Main pulse & 017 & 053 & 14 & 2.4 & 2.4 & 4.0 \\
\hline Number of beams for & & & & & & \\
\hline E =1.5 MJ & 60 & 50 & 40 & 24 & 24 & 20 \\
\hline $30 \mathrm{MJ}$ & 100 & 80 & 60 & 40 & 50 & 32 \\
\hline $59 \mathrm{MJ}$ & 240 & 140 & 120 & 80 & 100 & 60 \\
\hline Initial pulse duration $(\mu \mathrm{s})$ for & & & & & & \\
\hline $\mathrm{E}=15 \mathrm{MJ}$ & 20 & 15 & 10 & 10 & 15 & 10 \\
\hline $3.0 \mathrm{MJ}$ & 25 & 20 & 15 & 15 & 15 & 15 \\
\hline 5.9 MJ & 25 & 25 & 20 & 20 & 20 & 20 \\
\hline Direct capital cost (\$B) for & & & & & & \\
\hline $\mathrm{E}=1.5 \mathrm{MJ}$ & 031 & 032 & 0.43 & 0.56 & 034 & 0.75 \\
\hline $30 \mathrm{MJ}$ & 050 & 047 & 060 & 0.75 & 052 & 095 \\
\hline $59 \mathrm{MJ}$ & 083 & 075 & 088 & 1.06 & 085 & 127 \\
\hline
\end{tabular}
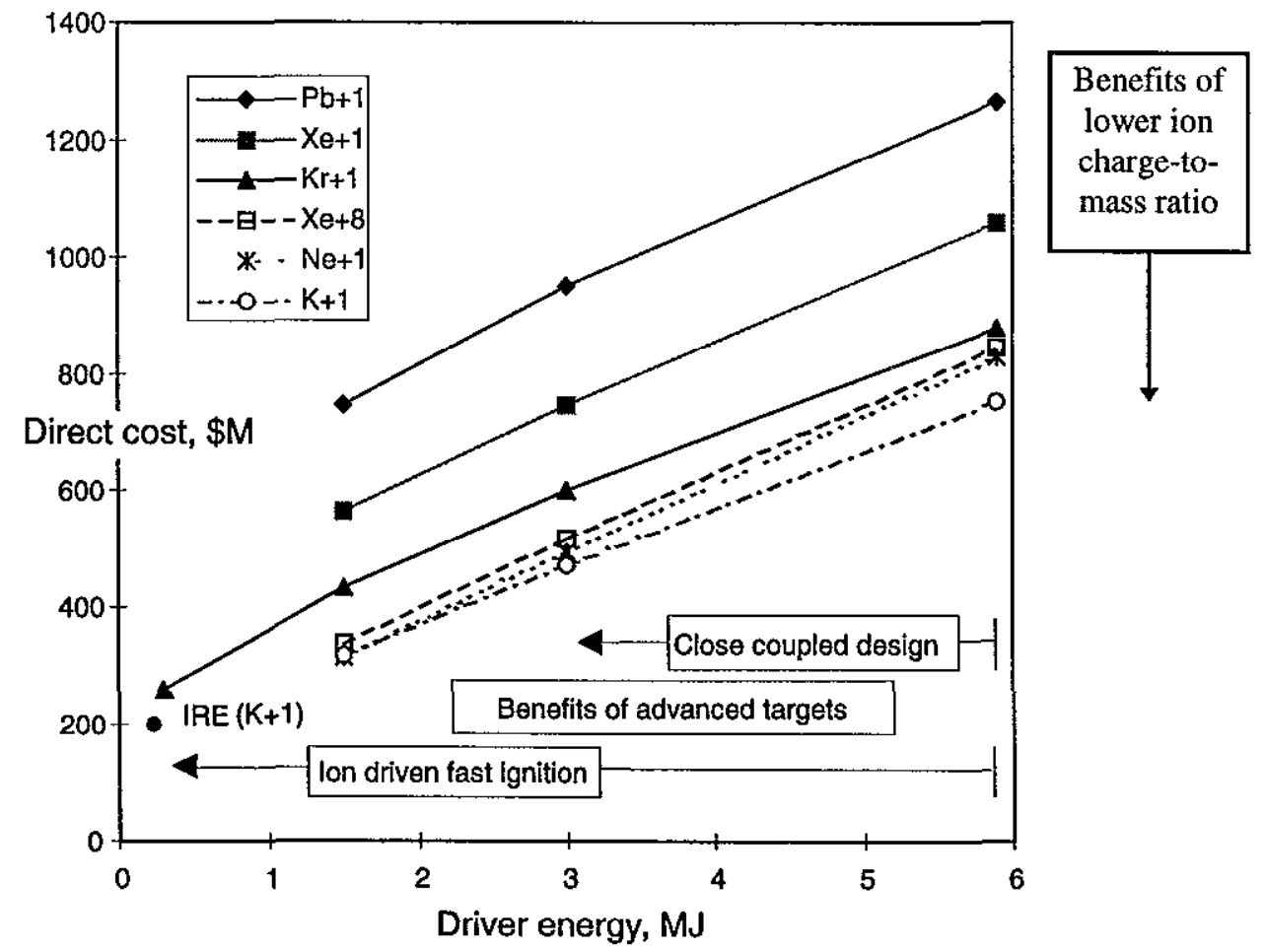

Fig 1 Driver cost versus energy for various ions Lower driver cost can be achieved by a combination of reducing the massto-charge ratio and improving target performance Closed-coupled, conventional hot-spot ignition targets could reduce the driver energy to $3 \mathrm{MJ}$ Ion driven fast ignition targets might require as little as $03 \mathrm{MJ}$ 


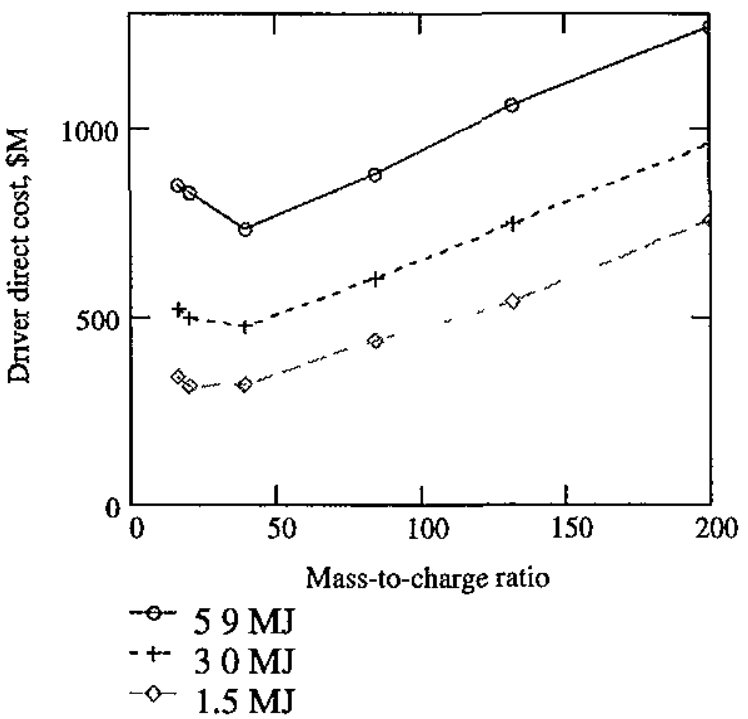

Fig 2 Driver cost versus ion mass-to-charge ratio for driver energies of 15,30 , and $59 \mathrm{MJ}$

smaller at low driver energies (as we expect), some redesign would be required (e g, more beams, smaller initial pulse duration), and the cost would increase from those shown here The three lowest cost cases, $\mathrm{Xe}^{+1}$, $\mathrm{Ne}^{+1}$, and $\mathrm{K}^{+1}$ do not meet the target spot size requirement under current final focus and transport model assumptions even for the $59 \mathrm{MJ}$ case

Figure 2 plots the driver cost as a function of the ion mass-to-charge ratio $(\mathrm{A} / \mathrm{q})$ for three driver energies, 15 , 30 , and $59 \mathrm{MJ}$ As indicated, the driver cost decreases linearly with decreasing $\mathrm{A} / \mathrm{q}$ down to about $\mathrm{A} / \mathrm{q}$ of 50 The minimum for all energies is around the $\mathrm{K}^{+1}$ case with an $\mathrm{A} / \mathrm{q}$ of 39 At $59 \mathrm{MJ}$, the minimum is very distinct while at the lower energies we see a general flattening of the curve with shallow minima If we could focus $\mathrm{K}^{+1}$ beams, we would have a near-optimum cost design Using $\mathrm{Kr}^{+1}$ would cost more $(+17 \%$ at $59 \mathrm{MJ}$ and $+28 \%$ at $30 \mathrm{MJ}$ ) but would be easier to focus and also relax demands on the injector due to the lower current per beam (1 5 to 18 times lower at 30 and $59 \mathrm{MJ}$, respectively)

Figures 1 and 2 show that driver costs can be reduced by a combination of lower ion mass, increased charge state, and improved target designs that provide adequate gain at lower driver energy A recently completed "closecoupled" target design with $31 \mathrm{MJ}$ of beam energy was able to achieve nearly the same yield as the $59 \mathrm{MJ}$ design. ${ }^{11}$ The spot size requirement, however, is quite smaller $(<2 \mathrm{~mm})$ These trends all highlight the importance of increased R\&D on beam focusing

\section{COMPONENT COST REDUCTION}

In addition to the items discussed above, work is continuing at LBNL on component cost reduction Table IV shows a level-2 cost breakdown for the $59 \mathrm{MJ}$ $\mathrm{Kr}^{+1}$ design The single largest cost item is the energy storage/pulse-forming-network cost, accounting for $\sim 21 \%$ of the driver equipment cost (Instrumentation \& Controls and Assembly and Installation are calculated as a multiplier of the driver equipment subtotal ) Reducing the cost from the currently assumed $\$ 10 / \mathrm{J}$ to $\$ 5 / \mathrm{J}$ would reduce the estimated driver cost by $\sim 10 \%$, and if we could achieve a $\$ 1 / \mathrm{J}$ level, the cost would be $20 \%$ lower The next largest cost item is Metglas, which is currently costed at $\$ 5 / \mathrm{kg}$ and represents $16 \%$ of the driver cost This cost already assumes cost savings resulting from large quantity purchases, and it is unlikely that there is significant downside potential here All of the other components are less than $10 \%$ of the driver cost Continued work on component cost reduction will be important in all areas

Table IV Cost breakdown for $59 \mathrm{MJ}, \mathrm{Kr}^{+1}$ driver

\begin{tabular}{|l|r|r|r|}
\hline Subsystem & \multicolumn{3}{|c|}{ Direct Cost, \$M } \\
\hline 1. Injector & & & $\mathbf{2 6}$ \\
\hline 2. Magnetic Focus Section & & & $\mathbf{5 0 2}$ \\
\hline 21 Quad Transport & & 119 & \\
\hline Magnets & 58 & & \\
\hline Cyrostats & 26 & & \\
\hline Refrigeration & 36 & & \\
\hline 22 Accelerator Modules & & 186 & \\
\hline Metglas & 97 & & \\
\hline Structures & 58 & & \\
\hline Insulators & 30 & & \\
\hline 2.3 Accel. Power Supplies & & 164 & \\
\hline Pulsers (switches) & 37 & & \\
\hline Storage and PFN & 127 & & \\
\hline 2.4 Vacuum systems & & 33 & \\
\hline 3. Final Transport & & & $\mathbf{6 7}$ \\
\hline 3.1 Quad magnetic & & 8 & \\
\hline 32 Dipole Magnetic & & 13 & \\
\hline 3.3 Cryostat & & 13 & \\
\hline 3.4 Refrigeration & & 16 & \\
\hline 3.5 Vacuum System & & 17 & \\
\hline 4. Final Focus Magnets & & & $\mathbf{8}$ \\
\hline Driver Equipment Subtotal & & & $\mathbf{6 0 2}$ \\
\hline Allowance for I\&C & & & $\mathbf{7 4}$ \\
\hline Allow. for Installation & & & $\mathbf{2 0 3}$ \\
\hline Total Direct Cost & & & $\mathbf{8 7 8}$ \\
\hline
\end{tabular}




\section{SENSITIVITY STUDIES}

Table $\mathrm{V}$ shows the sensitivity of the driver cost for the $59 \mathrm{MJ} \mathrm{Kr}^{+1}$ case to variations in key design parameters The percent change in cost from the result given in Table IV is given for a $+/-50 \%$ change in the reference case design parameter For this particular design point, the driver cost is most sensitive to reducing the quad field in the accelerator section of the driver, the cost increases by $\sim 12 \%$ if the field at the windings is reduced from 35 to $175 \mathrm{~T}$ All other variations have less than a $5 \%$ effect on the cost

Table V Sensitivity to design parameter changes

\begin{tabular}{|l|c|c|}
\hline \multicolumn{1}{|c|}{$\begin{array}{c}\text { Design Variable } \\
\text { (Reference Value = RV) }\end{array}$} & \multicolumn{2}{c|}{$\begin{array}{r}\text { Change in Capital } \\
\text { Cost at } \\
\mathbf{0 . 5 x} \mathbf{~ R V}\end{array}$} \\
\hline 1.5x RV \\
\hline Initial pulse duration $(20 \mu \mathrm{s})$ & $+4 \%$ & $+1 \%$ \\
\hline Number of beams (120) & $+3 \%$ & $+3 \%$ \\
\hline Accelerator quad field (3.5 T) & +12 & $+4 \%$ \\
\hline Final transport quad field (3.5 T) & $+4 \%$ & $+<1 \%$ \\
\hline
\end{tabular}

\section{INTEGRATED RESEARCH EXPERIMENT}

The systems model is also being used to evaluate design options for a near-term development facility called the Integrated Research Experiment (IRE) The goal of the IRE is to demonstrate an integrated test of beam transport and focusing onto a target plane (not DT targets) at $5 \mathrm{~Hz}$ We investigated various approaches to getting a low-cost facility with 10 's to 100 's of $\mathrm{kJ}$ of beam energy $\mathrm{A} \mathrm{K}^{+1}$ case using 16 beams could provide $200 \mathrm{~kJ}$ at an estimated direct cost of $\sim \$ 200 \mathrm{M}$ and would have the benefit of building on current injector design experience. To get a small spot size, the focal length would be shorter than in a chamber for a power plant ( $\sim \mathrm{m}$ or so). While these cost numbers need more review, our preliminary assessment indicates that some costs may be higher for the near-term machine, but those could be balanced by some design changes (e g., cold bore transport in the drift compression section) that would reduce costs, so the bottom line numbers are probably reasonable

\section{CONCLUSIONS}

We now have a useful systems analysis tool for investigating ion driver designs for IFE This paper has summarized some of the key findings of our work to date Although much work is needed in developing better models for many aspects of the driver (e $\mathrm{g}$, the injector costing, the final focus modeling, capacitor costs versus pulse length and lifetime, etc), we have combined our best current understanding and have been able to use the code to address some important design options (e g, front-end designs, ion mass, charge state, etc ) and to evaluate the impact of various assumptions (cost uncertainties and sensitivities) and new developments (e $\mathrm{g}$, new target design requirements)

\section{ACKNOWLEDGMENTS}

I would like to thank my colleagues in the heavy ion fusion programs at Lawrence Livermore National Laboratory and Lawrence Berkeley National Laboratory for their assistance, particularly Roger Bangerter (LBNL), Andy Faltens (LBNL), and Grant Logan (LLNL) Work performed under the auspices of the US Department of Energy by LLNL under Contract No W-7405-Eng-48

\section{REFERENCES}

1 W R Meier, "HIBEAM - Heavy Ion Beams for Energy Applications Model," LLNL report, UCID (June, 1998)

2 D J Dudziak, W W Saylor, and W B Herrmannsfeldt, "U S heavy-ion fusion systems assessment project overview," Fusion Technol, 13, (Feb 1988) 207

3 D S Zuckerman, D E Driemeyer, L M. Waganer, and D J Dudziak, "An induction linac driven heavy-ionfusion systems model," Fusion Technol, 13 (Feb 1988) 217

4. J Hovingh, V O Brady, A Faltens, and D Keefe, and E P Lee, "Heavy-ion linear induction accelerators as drivers for inertial fusion power plants," Fusion Technol, 13 (Feb 1988) 255

5 R L Bieri, M J Monsler, W R Meier, and L Stewart, "Heavy-ion driver design and scaling," Fusion Technol, 21 (May 1992) 1583

6 J J Barnard et al, "Study of Recirculating Induction Accelerators as Drivers for Heavy Ion Fusion," LLNL report UCRL-LR-108095 (September 21, 1991).

7 Tabak, Callahan-Miller, Ho, Zimmerman, submitted to Nuc Fusion

8 Tabak, Callahan-Miller, "Distributed Radiator Heavy ion Target Designs," Proceedings $12^{\text {th }}$ International Symposium on Heavy Ion Inertial Fusion (Heidelberg, Germany, September 24-27, 1997) to be published in Nuc Inst and Methods A

9 Tabak, Callahan-Miller, submitted to Phys of Plasmas

10. W R Meier, $R O$ Bangerter and A. Faltens, "An Integrated Systems Model for Heavy Ion Drivers," Proceedings $12^{\text {th }}$ International Symposium on Heavy Ion Inertial Fusion (Heidelberg, Germany, Sept 24-27, 1997) to be published in Nuc Inst and Methods A

11 D Callahan-Miller, LLNL, personal communication (May, 1998) 